\title{
Geoelectric monitoring at the Boulder magnetic observatory
}

\author{
Cletus C. Blum ${ }^{1}$, Timothy C. White ${ }^{1}$, Edward A. Sauter ${ }^{1}$, Duff C. Stewart ${ }^{1}$, Paul A. Bedrosian ${ }^{2}$, and Jeffrey J. Love \\ ${ }^{1}$ US Geological Survey, Geomagnetism Program, Box 25046 MS 966 DFC, Denver, Colorado 80225, USA \\ ${ }^{2}$ US Geological Survey, Crustal Geophysics and Geochemistry Science Center, P.O. Box 25046 MS 964 DFC, \\ Denver, Colorado 80225, USA
}

Correspondence to: Jeffrey J. Love (jlove@usgs.gov)

Received: 14 March 2017 - Discussion started: 7 June 2017

Revised: 31 August 2017 - Accepted: 14 September 2017 - Published: 2 November 2017

\begin{abstract}
Despite its importance to a range of applied and fundamental studies, and obvious parallels to a robust network of magnetic-field observatories, long-term geoelectric field monitoring is rarely performed. The installation of a new geoelectric monitoring system at the Boulder magnetic observatory of the US Geological Survey is summarized. Data from the system are expected, among other things, to be used for testing and validating algorithms for mapping North American geoelectric fields. An example time series of recorded electric and magnetic fields during a modest magnetic storm is presented. Based on our experience, we additionally present operational aspects of a successful geoelectric field monitoring system.
\end{abstract}

\section{Introduction}

Geoelectric fields are induced in the Earth's electrically conducting interior by time-dependent geomagnetic field variation sustained by dynamic processes operating in the ionosphere and magnetosphere. This induction occurs all the time, during both magnetically calm and stormy conditions. During intense storms, induced geoelectric fields can drive quasi-direct currents in bulk electric-power grids of sufficient strength to interfere with their operation, sometimes even causing blackouts and damaging transformers (e.g., Boteler et al., 1998; Piccinelli and Krausmann, 2014). Notably, the magnetic storm of March 1989 (e.g., Allen et al., 1989) caused the collapse of the Hydro-Québec power-grid system in Canada, leaving 6 million people without electricity (Bolduc, 2002; Béland and Small, 2005). More recently, the Halloween storm of October 2003 caused operational failures in parts of the Swedish power-grid system (Pulkkinen et al., 2005). Some scenario analyses anticipate that the future occurrence of a rare but extremely intense magnetic superstorm could cause widespread and long-lasting loss of electric power (e.g., Kappenman, 2012) and entail substantial economic cost (e.g., Baker et al., 2008).

In support of a project for modeling and evaluating geoelectric hazards (e.g., Thomson, 2007; Love et al., 2014), in June 2016 the Geomagnetism Program of the US Geological Survey (USGS) commenced long-term geoelectric field monitoring at its Boulder, Colorado, magnetic observatory (BOU). The Boulder geoelectric monitoring project partially fulfills a directive in the United States National Space Weather Action Plan (NSTC, 2015; Goal 5.5.4) (one of many given to different agencies) for the Department of Interior to "assess and pilot a geoelectric monitoring capability". It is further consistent with strategic goals of the USGS Hazard Mission for enhancing observations, pursuing fundamental understanding, and improving hazard assessments (Holmes et al., 2013, Goal 1). Geoelectric field monitoring is a natural extension of the geomagnetic monitoring that is already the responsibility of the USGS Geomagnetism Program (Love and Finn, 2011), and it is similar to long-term geoelectric monitoring projects supported in other countries, including Great Britain (Kelly et al., 2013) and Japan (Fujii et al., 2015), and to shorter-term campaign-style measurements common to magnetotelluric surveys (e.g., Ferguson, 2012). From 1932 to 1942, analog geoelectric measurements were supported at the Tucson magnetic observatory (Rooney, 1949); from 1988 to 1995, geoelectric monitoring was performed in Parkfield, California, as a part of an earthquake research project (Park, 1997). Otherwise, there has been very little multi-year geoelectric monitoring carried out in the United States. 


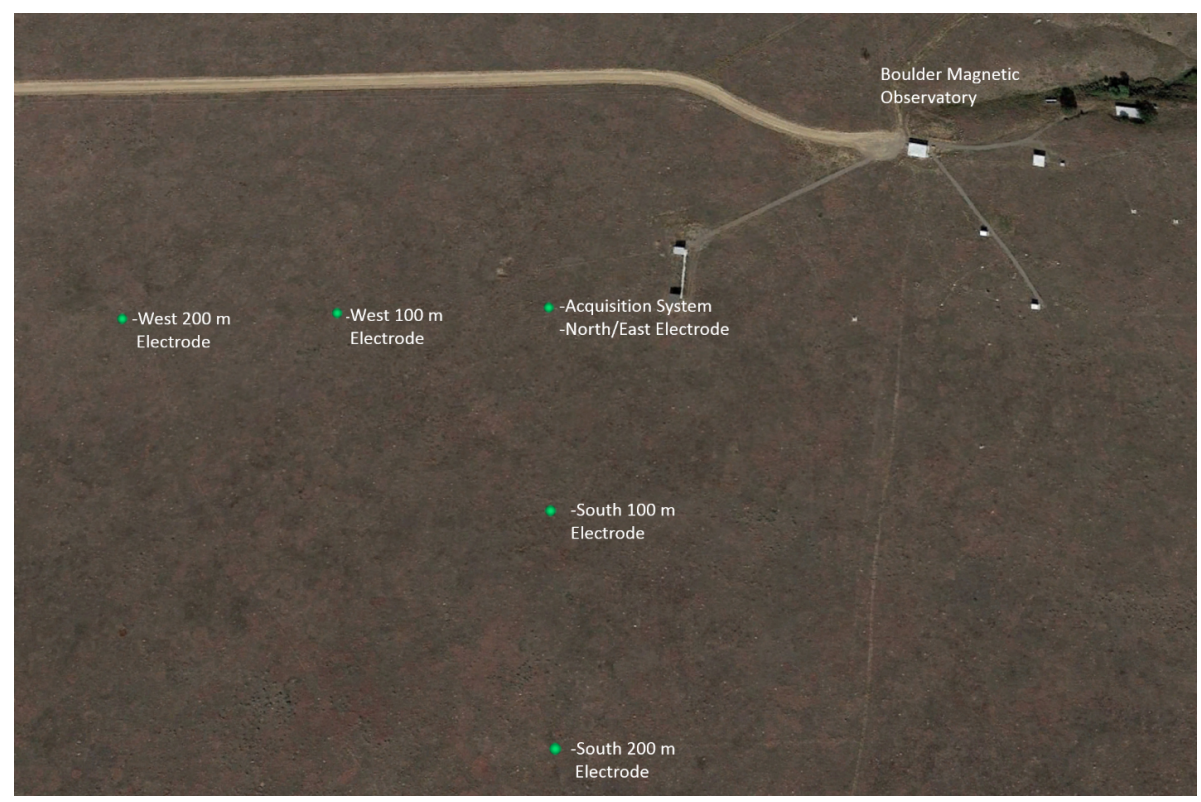

Figure 1. Map of geoelectric monitoring deployment at the Boulder observatory. North is up.

\section{The Boulder site}

The Boulder magnetic observatory facility (Love et al., 2015) is located on a flat-top butte, north of the city of Boulder, Colorado, and east of the United States Rocky Mountains. The land is rocky and sandy, sparsely covered with grass and cacti. The climate is semiarid; summers can be hot $\left(>30^{\circ} \mathrm{C}\right.$ is common) with occasional thunderstorms; winters can be cold (often $<-5^{\circ} \mathrm{C}$ ) with occasional snowfall. The Boulder observatory is 1 of 14 supported by the USGS Geomagnetism Program, and it is part of the International Real-time Magnetic Observatory Network (www.intermagnet.org; Love and Chulliat, 2013). The observatory is also used by Geomagnetism Program engineers and technical staff to develop and test new sensors, acquisition systems, and operational procedures. The geoelectric monitoring system described herein is located southwest of the observatory's office building and primary geomagnetic monitoring systems; see Fig. 1.

\section{Electrodes and their installation}

Geoelectric data are obtained by measuring the voltage between pairs of non-polarizable electrodes over time. For geoelectric monitoring at Boulder, Borin Stelth ${ }^{\circledR}$ two silversilver chloride $(\mathrm{Ag}-\mathrm{AgCl})$ electrodes were selected for their thermal stability, low noise characteristics, long expected service life ( $>30$ years), and relatively large surface area $\left(200 \mathrm{~cm}^{2}\right)$; see Fig. 2. Electrode noise levels have been estimated to be significantly less than $1 \mathrm{mV}$ based upon longterm measurements of electrode potential in a temperatureand salinity-controlled tank. In June 2016, six electrodes were installed: two located near the data acquisition system

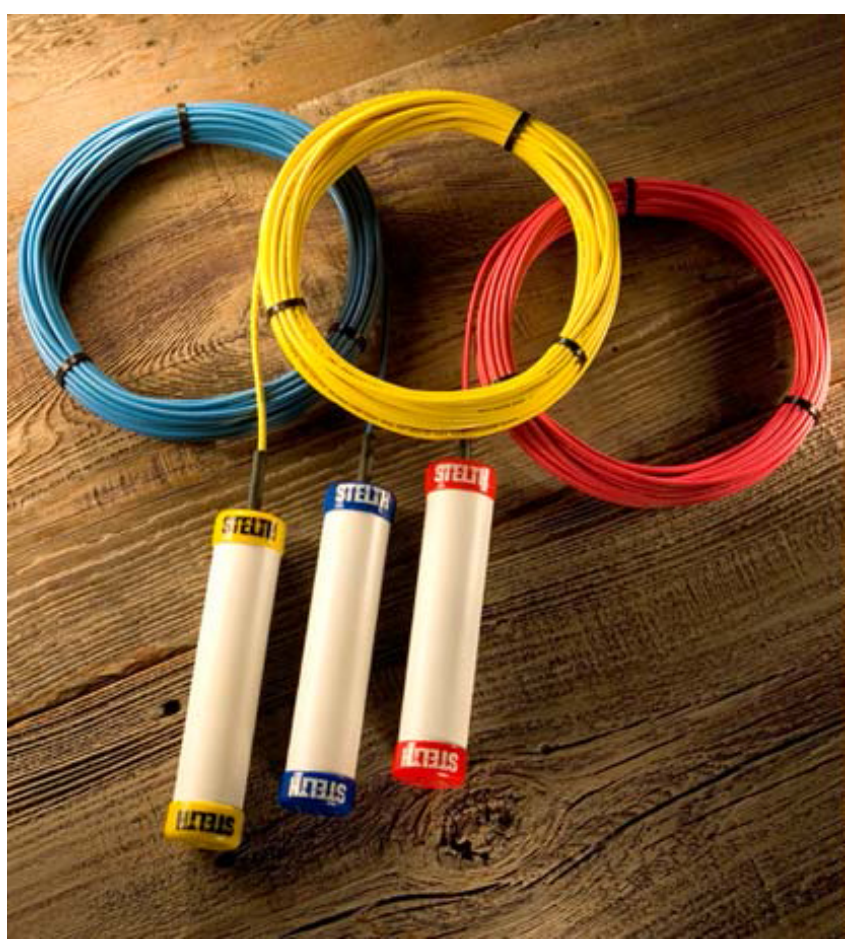

Figure 2. The Borin Stelth ${ }^{\circledR}$ electrodes used for geoelectric monitoring at the Boulder observatory.

and one each located 100 and $200 \mathrm{~m}$ to the west and south from there. The electrodes were buried to reduce grounding changes caused by time variation in soil moisture content and temperature that can impart unwanted types of voltage variation. As shown schematically in Fig. 3, at each electrode lo- 


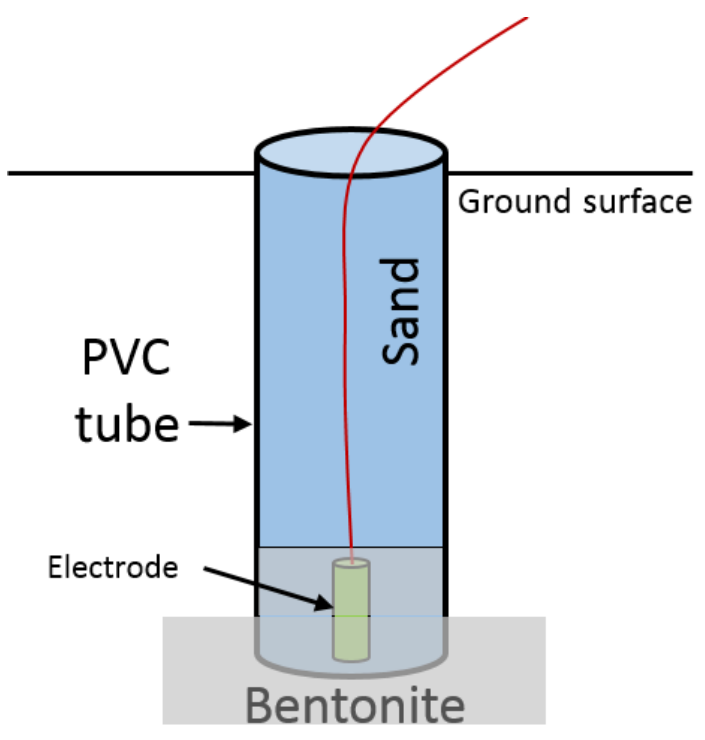

Figure 3. Schematic of electrode installation.

cation, a $1 \mathrm{~m}$ deep hole was dug; this was then partially filled with a thick layer of bentonite clay, a substance that is very absorbent and commonly used as a barrier against groundwater. A $20 \mathrm{~cm}$ diameter, $1.25 \mathrm{~m}$ long, open-ended, polyvinyl chloride (PVC) pipe was placed vertically in the hole and in contact with the bentonite; an electrode was placed in the bottom of the tube with connecting wires leading out the top end. The tube was then partially filled with additional bentonite until the electrode was covered; the rest of the tube was backfilled with sand; the space around the outside PVC tube was filled with native rock and sand. The electrodes are connected to the acquisition system using shielded coaxial cables further protected by PVC conduit. Two electrodes are located near the acquisition system; one is used for the $100 \mathrm{~m}$ dipoles and the other is used for $200 \mathrm{~m}$ dipoles. Additional empty PVC pipes were installed in parallel for possible future electrode emplacement that might be needed for testing and to provide redundancy. Contact resistances between each pair of electrodes range from 200 to $300 \Omega$.

\section{Data acquisition and management}

Electrode voltage measurements are acquired using the $\mathrm{Ob}$ servation Reconfigurable Input and Output System (ObsRIO) that USGS engineers developed in-house using the CompactRIO (cRIO) hardware platform manufactured by National Instruments Corporation; the system is solar powered (see Fig. 4). The two standard data types acquired by $\mathrm{Ob}-$ sRIO are discrete $10 \mathrm{~Hz}$ values and discrete $1 \mathrm{~s}$ values. Ten hertz data values are formed from a digital filtering of $100 \mathrm{~Hz}$ analog-filtered samples, while $1 \mathrm{~Hz}(1 \mathrm{~s})$ values are formed from a digital filtering of $10 \mathrm{~Hz}$ values. This data construction process reduces aliasing from geoelectric variation with peri-
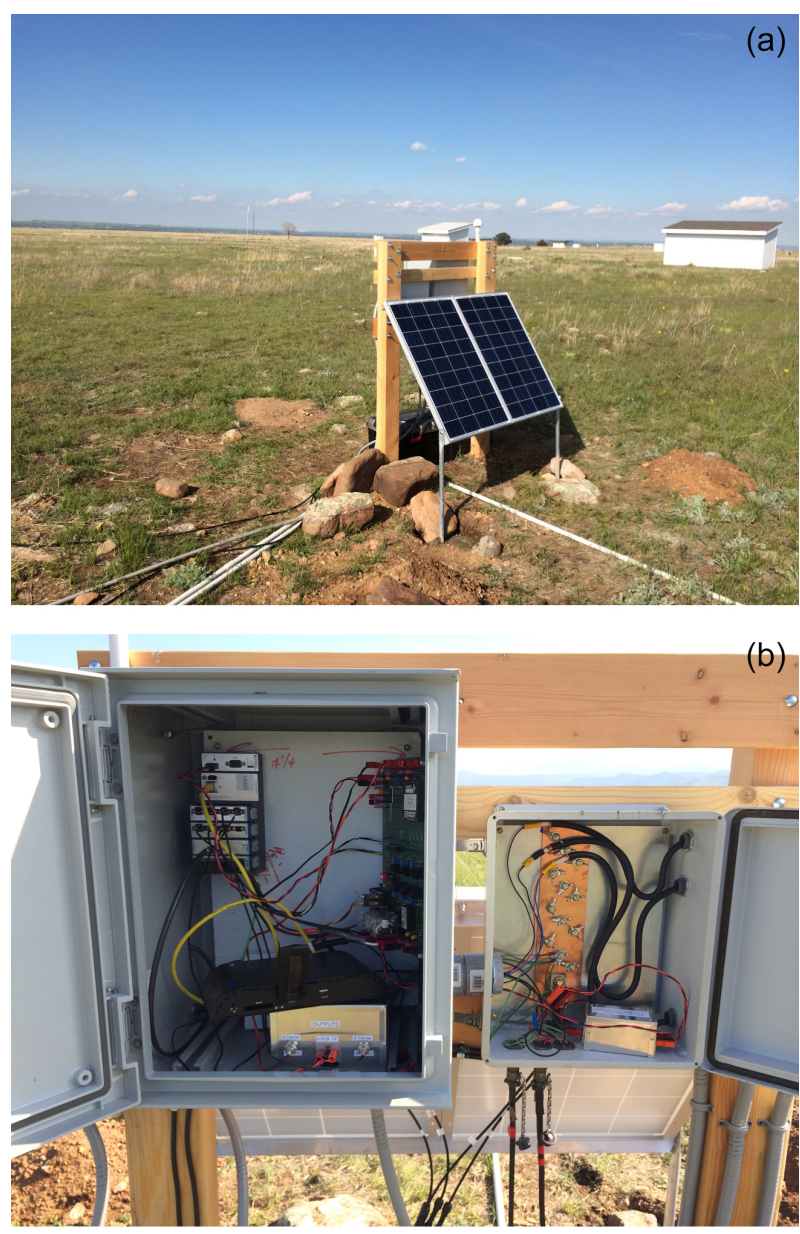

Figure 4. Geoelectric field data acquisition system at the Boulder observatory. (a) View to the northeast of the data acquisition system. Electric field lines, protected by PVC conduit, extend west and south. (b) Interior view of data acquisition system in environmentally sealed enclosures. Electric and optionally magnetic inputs are brought into the right enclosure with shielding tied to the observatory grounding system. The left enclosure containing the ObsRIO is in the upper left, the switching power-source controller is on the right, and a cellular model in the center.

ods of less than $0.1 \mathrm{~s}$ (frequencies greater $10 \mathrm{~Hz}$ ). Data from the Boulder ObsRIO systems are transmitted to the USGS database system, EdgeCWB (Patton et al., 2015), in Golden, Colorado, via internet protocols in near-real time. Geomagnetism Program personnel make regular checks of the Boulder geoelectric data to guard against artificial interference and to ensure continuity of operations.

\section{Example data}

In Fig. 5 we show 3 days of Boulder geomagnetic and geoelectric data recording a geomagnetic storm that occurred in October 2016. In global terms, the storm attained a maximum $\mathrm{Dst}=-104 \mathrm{nT}$ and a maximum $\mathrm{Kp}=6$. Local to Boulder, 

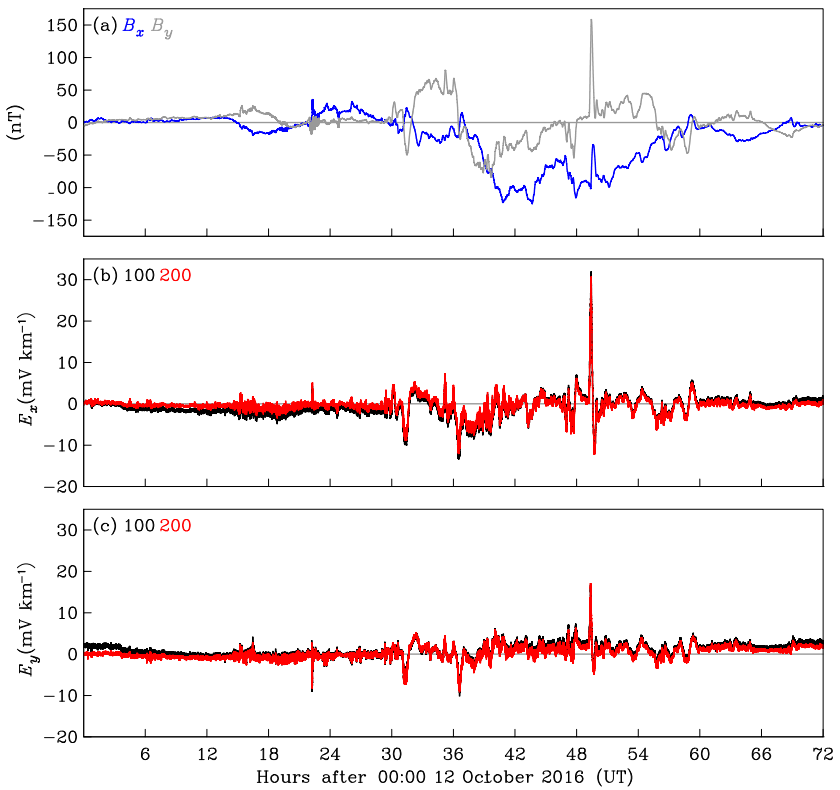

Figure 5. Three days of geomagnetic and geoelectric field variation recorded at the Boulder observatory: (a) north (blue) and east (gray) geomagnetic components; (b) north geoelectric component, 100 (black) and 200 (red) dipole; (c) east geoelectric component, 100 (black) and 200 (red) dipole.

however, the east geomagnetic component saw a very abrupt and high amplitude signal ( $\sim 150 \mathrm{nT})$, which induced a large geoelectric signal in the north geoelectric component. The lowest-frequency (diurnal) signals observed in the geomagnetic time series are not reproduced in the geoelectric data due to a $30000 \mathrm{~s}$ high-pass analog filter within the acquisition system. All the measured geoelectric field variation is well correlated with geomagnetic variation and is consistent with induction in the solid Earth. Note, furthermore, the consistency between the geoelectric time series for the 100 and $200 \mathrm{~m}$ dipoles.

\section{Using the data}

A high priority for monitoring and assessing geoelectric hazards is the development of capabilities for making maps of the geoelectric field, especially in real time (e.g., NSTC, 2015; Action 5.5.6). One approach to regional- and continental-scale geoelectric field mapping is convolving maps of Earth impedance with maps of geomagnetic activity (e.g., Thomson, 2007; Love et al., 2014). Toward this end, long-term surface geoelectric field data, spanning both quiet and storm times, are critical to validating predicted field data and to benchmarking different modeling approaches (e.g., Kelbert et al., 2017; Bonner and Schultz, 2017). Additionally, surface impedance functions can be calculated from synchronous electric and magnetic time series, as is commonly done with magnetotelluric survey data. Long-term (months to years) geoelectric time series data, as described here, constrain estimates of surface impedance to longer periods than traditional magnetotelluric studies, facilitating investigations into deep-Earth conductivity structure. Finally, continuous recording of geoelectric and geomagnetic time series data, particularly at sampling frequencies sufficient to capture the magnetotelluric "dead band" $(10-0.1 \mathrm{~Hz})$, can serve as remote referencing for regional magnetotelluric surveys (e.g., Gamble et al., 1979; Egbert 1997). The availability of such data in near-real time can reduce the logistics and costs associated with such surveys, and it can lead to improved data quality.

\section{Operational aspects of long-term electric field monitoring}

Long-term electric-field monitoring introduces technical challenges that are distinct from traditional magnetotelluric campaign or array deployments. As with other monitoring studies, power supply, telemetry, and system reliability are important design considerations for a successful electricfield monitoring system. Furthermore, long-term electrode deployment adds additional critical design elements, including thermal stability, moisture stability, and lightning suppression. We describe below aspects of the Boulder installation that we consider important to achieving continuous, stable, low-noise geoelectric field data.

Long-term electric-field measurements can be improved with the use of stable, low-noise, non-polarizable electrodes. A variety of electrode chemistries exist, with $\mathrm{Ag}-\mathrm{AgCl}$ and $\mathrm{Pb}-\mathrm{PbCl}_{2}$ being two of the more commonly used types. Both of these electrode types are known for their low noise levels, small thermal coefficients, and long-term stability (e.g., Clerc et al., 1998; Petiau, 2000). The Earth environment in which the electrodes are placed is additionally important. In particular, greater thermal and moisture stability reduces non-inductive signals (e.g., diurnal signals due to surface temperature variations). Toward this end, the USGS electrodes are buried $1 \mathrm{~m}$ deep. Electrode noise further scales with the contact resistance between the electrode and the ground. To minimize both, soil within an area of $0.5 \mathrm{~m}^{2}$ was removed and replaced with an electrically conducting bentonite slurry. A $1.25 \mathrm{~m}$ long (1.0 m below ground) PVC tube was emplaced into the bentonite to facilitate the installation and, if necessary, replacement of the electrodes. The electrodes were placed into the bentonite slurry, covered with an additional layer of bentonite, and the remainder of the PVC tube was filled with sand. Caps were subsequently installed to seal the tube and prevent loss of moisture. Additional electrodes were similarly installed for redundancy.

The electrodes are connected via coaxial cable to the data acquisition system. Coaxial cable is selected to reduce the introduction of capacitive noise via the long cable length deployed for this application. The cable shields are grounded 
near the data acquisition system but isolated at the electrode ends to avoid creating ground loops through the shielding. The coaxial cable was further installed in PVC conduit to protect the cables from damage due to wildlife. Strain relief was added to the PVC conduit at $30 \mathrm{~m}$ intervals to prevent damage to the conduit and cable that can be caused by seasonal thermal expansion and contraction.

Lightning suppression, attenuation, and protection are of the utmost importance in collecting continuous long-term geoelectric field data. On two separate occurrences, buildings at the Boulder observatory have been struck by lightning. Effective measures must be taken to protect recording systems from damage under such conditions. The USGS has installed a grounding system at the data acquisition site, consisting of a large steel ground rod driven $2.34 \mathrm{~m}$ deep. The coaxial shields are all connected to this ground, which provides an electrical path for lightning-induced signals and other noise sources incident on the shields. The electrodes are further connected to a pre-amplifier and lightning isolation circuit board. The board was originally designed for the NIMS portable MT system, developed by Narod Geophysics Ltd. There are two components of lightning protection integrated on this board. First are a series of $75 V_{\mathrm{DC}}$ spark gap devices, connected individually to each incoming electrode connection. Additionally, varistors are used in a suppression mode to shunt excessive currents incident on the incoming channels. This board has been used to collect hundreds of thousands of hours of data for the EarthScope US Array program with very few cases of failure from lightning.

Amplification and filtering can be an important component of electric-field monitoring depending upon the application as well as the sensitivity and dynamic range of the data acquisition system. Quiet-time electric-field amplitudes are on the order of $0.1 \mathrm{mV} \mathrm{km}^{1-}$ or less; hence measured voltages across electrode pairs separated by $\sim 100 \mathrm{~m}$ may be on the order of $0.01 \mathrm{mV}$. Instrument gain is commonly used to amplify the raw signals; the gain at the Boulder monitoring station is a factor of 10. Filtering may also be beneficial to obtaining quality electric-field data. There are two analog filters incorporated within the Boulder data acquisition system. A notch filter attenuates $60 \mathrm{~Hz}$ signal, common to North America's power distribution network, by a factor of at least $20 \mathrm{~dB}$. An additional analog high-pass filter, with a time constant of roughly $10.5 \mathrm{~h}$, can optionally be turned on. This filter may be used to attenuate long-period signals, including diurnal variation arising from thermal drift in the electrodes and long-term drift in grounding.

A low-noise, high input-impedance data acquisition system with moderately high sample rate is needed for geoelectric field monitoring. To meet this need we developed the ObsRIO based on the cRIO hardware platform manufactured by National Instruments. A key design aspect of the ObsRIO platform is its modularity and ability to change configurations in response to rapidly changing scientific needs. Minimal development time is required to create new images of
ObsRIO for different scientific applications. The USGS has, for example, designed a portable magnetotelluric variant of the system which acquires both electric and magnetic field data and is battery powered.

The ObsRIO employs four-channel simultaneous sampling on a 24 bit, \pm 10 VDC (direct current voltage) analogto-digital converter (ADC, NI 9239). The ADC is configured to sample at a frequency of $10 \mathrm{kHz}$. A box-car filter is used to decimate the data from 10 to $1 \mathrm{kHz}$ and ultimately to separate 100,10 , and $1 \mathrm{~Hz}$ data output streams for logging and transmission. A GPS clock was used to discipline the FPGA (field-programmable gate array) clock, a process where the GPS signal is used to constantly calibrate the FPGA clock. Time-stamped samples are passed into a first-in, first-out (FIFO) memory buffer for further processing, logging, and transmission on the real-time controller for the cRIO chassis. Pairing the ObsRIO system with a cellular device allows for real-time data collection and transmission.

The data acquisition system was finally designed with automated switching power-source control. ObsRIO automatically charges one battery, while powering the system from a separate battery electrically isolated from the charging source. A series of programmable relays and low-resolution ADCs are used to set the power supply state for the system and switch charging and load batteries as needed. This is an important aspect of the ObsRIO system, as noisy power sources (such as solar) are kept from contaminating the desired geoelectric fields. This feature is additionally critical to campaign style deployments, which rely on batteries and solar power for power.

Data availability. Boulder geoelectric field data can be viewed on the USGS geomagnetism plots page (http://geomag.usgs.gov/plots/, USGS Geomagnetism Program, 2016) and downloaded from (http: //dev-geomag.cr.usgs.gov/ws/edge/).

Competing interests. The authors declare that they have no conflict of interest.

Disclaimer. Any use of trade, firm, or product names is for descriptive purposes only and does not imply endorsement by the US government.

Special issue statement. This article is part of the special issue "The Earth's magnetic field: measurements, data, and applications from ground observations (ANGEO/GI inter-journal SI)". It is a result of the XVIIth IAGA Workshop on Geomagnetic Observatory Instruments, Data Acquisition and Processing, Dourbes, Belgium, 4-10 September 2016. 
Acknowledgements. We thank Jill McCarthy and Janet L. Slate for reading a draft manuscript. We thank Thomas Theissen from Borin Manufacturing Inc. for providing the electrodes used at the Boulder magnetic observatory.

Edited by: Kusumita Arora

Reviewed by: Anatoly Soloviev and Nandini Nagarajan

\section{References}

Allen, J., Frank, L., Sauer, H., and Reiff, P.: Effects of the March 1989 solar activity, EOS Transactions of the American Geophysical Union, 70, 1479, 1486-1488, https://doi.org/10.1029/89EO00409, 1989.

Baker, D. N., Balstad, R., Bodeau, J. M., Cameron, E., Fennell, J. E., Fisher, G. M., Forbes, K. F., Kintner, P. M., Leffler, L. G., Lewis, W. S., Reagan, J. B., Small, A. A., Stansell, T. A., and Strachan, L.: Severe Space Weather Events - Understanding Societal and Economic Impacts, 1-144, Natl. Acad. Press, Washington, DC, https://doi.org/10.17226/12507, 2008.

Béland, J. and Small, K.: Space weather effects on power transmission systems: The cases of Hydro-Québec and Transpower New Zealand Ltd, in: Effects of Space Weather on Technology Infrastructure, edited by: Daglis, I. A., Springer, Dordrecht, the Netherlands, chapter 15, 287-299, https://doi.org/10.1007/14020-2754-0_15, 2005.

Bolduc, L.: GIC observations and studies in the Hydro-Québec power system, J. Atmos. Solar-Terr. Phys., 64, 1793-1802, https://doi.org/10.1016/S1364-6826(02)00128-1, 2002.

Bonner IV, L. R. and Schultz, A.: Rapid prediction of electric fields associated with geomagnetically induced currents in the presence of three-dimensional ground structure: Projection of remote magnetic observatory data through magnetotelluric impedance tensors, Adv. Space Res., 15, 204-227, https://doi.org/10.1002/2016SW001535, 2017.

Boteler, D. H., Pirjola, R. J., and Nevanlinna, H.: The effects of geomagnetic disturbances on electrical systems at the Earth's surface, Adv. Space Res., 22, 17-27, https://doi.org/10.1016/S02731177(97)01096-X, 1998.

Clerc, G., Petriau, G., and Perrier, F.: The Garchy 1995-1996 electrode experiment technical report, CNRS, Garchy, France, 1998.

Egbert, G. D.: Robust multiple-station magnetotelluric data processing, Geophys. J. Int., 130, 475-496, https://doi.org/10.1111/j.1365-246X.1997.tb05663.x, 1997.

Ferguson, I. J.: Instrumentation and field procedure, in: The Magnetotelluric Method, edited by: Chave, A. D. and Jones, A. G., Cambridge Univ. Press, Cambridge, UK, 421-479, 2012.

Fujii, I., Ookawa, T., Nagamachi, S., and Owada, T.: The characteristics of geoelectric fields at Kakioka, Kanoya, and Memambetsu inferred from voltage measurements during 2000 to 2011, Earth Planets Space, 67, 62, https://doi.org/10.1186/s40623-015-0241z, 2015.

Gamble, T. D., Goubou, W. D., and Clarke, J.: Magnetotellurics with a remote magnetic reference, Geophysics, 44, 53-68, 1979.

Holmes, R. R., Jones, L. M., Eidenshink, J. C., Godt, J. W., Kirby, S. H., Love, J. J., Neal, C. A., Plant, N. G., Plunkett, M. L., Weaver, C. S., Wein, A., and Perry, S. C.: US Geological Survey Natural Hazards Science Strategy - Promoting the Safety, Security, and Economic Well-Being of the Nation, US Geological Survey Circular, 1-79, 2013.

Kappenman, J. G.: A perfect storm of planetary proportions, IEEE Spectrum, 49, 26-31, 2012.

Kelbert, A., Balch, C. C., Pulkkinen, A., Egbert, G. D., Love, J. J., Rigler, E. J., and Fujii, I.: Methodology for time-domain estimation of storm time geoelectric fields using the 3-D magnetotelluric response tensors, Adv. Space Res., 15, 874-894, https://doi.org/10.1002/2017SW001594, 2017,.

Kelly, G., Shanahan, T., Beggan, C., Swan, A., and Thomson, A.: Early results from the UK geo-electric field monitoring project, The UK National Astronomy Meeting, General MIST Poster Session, P12.5, St. Andrews, 1-5 July 2013.

Love, J. J. and Chulliat, A.: An international network of magnetic observatories, EOS Transactions of the American Geophysical Union, 94, 373-374, https://doi.org/10.1002/2013EO420001, 2013.

Love, J. J. and Finn, C. A.: The USGS Geomagnetism Program and its role in space weather monitoring, Adv. Space Res., 9, S07001, https://doi.org/10.1029/2011SW000684, 2011.

Love, J. J., Rigler, E. J., Pulkkinen, A., and Balch, C. C.: Magnetic storms and induction hazards, EOS Transactions of the American Geophysical Union, 95, 445-446, https://doi.org/10.1002/2014EO480001, 2014.

Love, J. J., Finn, C. A., Pedrie, K. L., and Blum, C. C.: The Boulder magnetic observatory, US Geological Survey Open-File Report 2015-1125, 1-8, https://doi.org/10.3133/ofr20151125, 2015.

NSTC: National Space Weather Action Plan, Executive Office, National Science and Technology Council, Washington, DC, 1-38, 2015.

Park, S. K.: Monitoring resistivity change in Parkfield, California 1988-1995, J. Geophys. Res., 102, 24545-24559, https://doi.org/10.1029/97JB02080, 1997.

Patton, J. M., Ketchum, D. C., and Guy, M. R.: An overview of the National Earthquake Information Center acquisition software system, Edge/Continuous Waveform Buffer, Open-File Report 2015-1174, 1-10, https://doi.org/10.3133/ofr20151174, 2015.

Petiau, G.: Second generation of lead-lead chloride electrodes for geophysical applications, Pure Appl. Geophys., 157, 357-382, 2000.

Piccinelli, R. and Krausmann, E.: Space Weather and Power Grids - A Vulnerability Assessment, European Union, Luxembourg 153, 2014.

Pulkkinen, A., Lindahl, S., Viljanen, A., and Pirjola, R.: Geomagnetic storm of 29-31 October 2003: Geomagnetically induced currents and their relation to problems in the Swedish highvoltage power transmission system, Adv. Space Res., 3, S08C03, https://doi.org/10.1029/2004SW000123, 2005.

Rooney, W. J.: Earth-Current Results at Tucson Magnetic Observatory, 1932-1942, Carnegie Institute, Washington, DC, 1-309, 1949.

Thomson, A. W. P.: Geomagnetic hazards, in: Encyclopedia of Geomagnetism and Paleomagnetism, edited by: Gubbins, D. and Herrero-Bervera, E., Springer, Dordrecht, the Netherlands, 316319, https://doi.org/10.1007/978-1-4020-4423-6_117, 2007.

USGS Geomagnetism Program: Boulder electric field data, available at: https://dev-geomag.cr.usgs.gov/ws/edge/, 2016. 